\title{
A espiritualidade da arte celta: estudo do Escudo de Battersea sob a ótica Panofskyana
}

\author{
The spirituality of Celtic Art: Study of the Battersea Shield under the \\ Panofskyan optics
}

\author{
Maria Roseli Sousa Santosl \\ Lidia da Costa Valle ${ }^{2}$ \\ Willa da Silva Prazeres 3
}

\section{RESUMO}

\begin{abstract}
O artigo explora o tema: arte religiosa presente na produção artística céltica. Sabe- se que no período auge dos povos célticos, a ideia de arte e religião não era delineada como hoje. Sua produção de artefatos, armamentos de guerra, dentre outros, não estava desvinculada das noções de espiritualidade e culto aos Deuses. O objetivo central deste trabalho é compreender como a cosmovisão religiosa dos povos celtas está representada na produção do Escudo de Battersea, através da aplicação da iconologia Panofskyana: do sentido primário ou natural; secundário ou convencional e intrínseco ou conteúdo. Conclui-se que há uma intencionalidade religiosa nos artefatos célticos, assim como tudo no cotidiano desses povos era norteado pelo culto aos Deuses e sua cosmovisão espiritual.
\end{abstract}

Palavras-chave: Arte, Espiritualidade, Celta.

\begin{abstract}
The article explores the theme: religious art present in Celtic artistic production. It's known that in the heyday of Celtic people, the idea of art and religion wasn't outlined as it's today. Their artifacts and weapons of war weren't disconnected from their spirituality and worship of the Gods. The main objective of this work is to understand how the religious worldview of Celtic people is represented in the Battersea Shield production, through the application of Panofsky's iconology: the primary or natural meaning; secondary or conventional one and intrinsic or content. It's concluded that there's a religious intentionality in Celtic artifacts, just as everything in their daily life that was guided by the worship of the Gods and their spiritual worldview.
\end{abstract}

Key-words: Art, Spirituality, Celtic.

\footnotetext{
1 Doutora em Educação pela Universidade Federal do Pará e Professora Adjunta da Universidade do Estado do Pará. Contato: mroselisousa@ uepa.br.

2 Mestranda em Ciências da Religião na Universidade do Estado do Pará. Contato: lidiavallel@ @otmail.com.

3 Mestranda em Ciências da Religião na Universidade do Estado do Pará. Contato: willa.sprazeres@ hotmail.com. Artigo recebido em 31/03/2018 e aprovado em 13/08/2018.
}

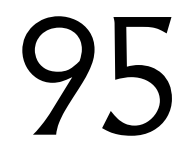




\section{Introdução}

A arte é uma invenção dos seres humanos para fazer sentido à vida, transforma realidades banais para além delas. Possibilita dar sentido a informações naturais da realidade, eleva os símbolos a significados que transcendem o próprio representado. A arte tem a capacidade de refutar fatos da história, a partir de diversas linguagens, sendo elas verbais e não-verbais: textos, cânticos, gestos, performances e imagens. Nesse sentido, a arte permite ao artista reproduzir e interiorizar o mundo a partir de um recurso material, e transformá-lo, produzindo mundos fictícios (HIGUET, 2015). Pode ser: expressionista, realista, abstrata, plástica, performática, musical, religiosa, cinematográfica e imagética. Apesar de a arte ter várias formas de expressão, a imagética sempre foi a mais utilizada. Principalmente no que tange aos artefatos de povos antigos, como dos celtas, que eram povos ágrafos (sem escrita), onde símbolos e imagens tornam-se preponderantes.

A imagem está entre a percepção verdadeira e o abstrato da coisa percebida. Não é a própria coisa, mas uma representação, que toma lugar do objeto, extinguindo distância e tempo ou a ausência de realidade e espaço. Etienne Higuet aponta duas categorias de imagens: as lingüísticas, a que se utiliza de signos, sendo polissêmica, flexível, universal, poética e lírica e as visuais propriamente ditas, que permitem ver o surgimento de algo no espaço, com riqueza sensorial e emotiva por parte do espectador (HIGUET, 2015). Unindo essas duas categorias de imagens, pode-se ter uma aliança, na qual a linguagem, no ato de leitura, necessita da recepção visual da expressão escrita. A imagem, então, insere-se na esfera linguística, funcionando como intermediário entre voz e olhar. Desta junção, segundo Higuet, tem-se a arte na religião. Essa união de sentidos entre religião e arte perpassa por várias facetas, desde a arte imagética à linguística não verbal, através do próprio tempo. Especialmente no caso aqui estudado, de uma antiga civilização ágrafa, da qual é comum se compreender suas narrativas míticas e pensamentos acerca da vida e do cosmo a partir das imagens e símbolos que estes deixaram registrados, pois a imagem também é linguagem - é sempre intermediadora, mesmo nas representações escritas - e, por si só, exprime um texto.

A arte religiosa, nesse contexto, transmite uma mensagem ao ser humano, a um grupo, à sociedade e ao ser religioso. Sendo essa uma mensagem de amor, de conhecimento, de historia e estória, carregada de símbolos, mitos e ritos. Desta forma, ela agrega valores além do próprio objeto que reinterpreta. Ela dá sentido, forma e recria imagens antes inalcançadas e inobjetáveis. Expressa a relação humana com o infinito da realidade, transforma elementos naturais ou do cotidiano em símbolos transcendentes, antecipa possibilidades e fragmentos do sagrado. A arte tem, ainda, o poder de ensinar a partir de suas formas, estilos e temas, sendo um objeto de fuga da realidade e de conforto. Tais representações têm o intuito de comunicar com o "todo" do ser humano, ou seja, com o sentimento do seu receptor, semelhante ao que ocorre quando se observa um objeto sagrado, objetos que expressam o Mistério, ou sua representação imagética (um quadro, uma foto, uma peça, ou um instrumento utilizado por divindades), que agem como intermediários entre o sujeito e o "Totalmente Outro", o Supremo ou Divino, como enaltece Rudolf Otto, no seu livro “O Sagrado" (2007).

Ao nos determos no estudo da arte religiosa, é possível apreender um construto de cultura visual de extrema importância atualmente pelos variados avanços acerca do entendimento da visualidade da cultura, ou seja, a afirmação de que as formas de recepção da arte, das imagens, signos, símbolos, de cenas do cotidiano e das diversas experiências visuais como um todo estão ligadas a cada contexto histórico e cultural da humanidade (SÉRVIO

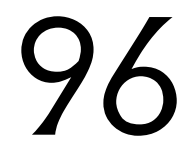


2014). O estudo da experiência visual, portanto, não se limita a imagens, fotografias ou obras de artes pintadas, mas sim a toda experiência cultural e social mediada pela visão. W.J.T. Mitchell (2002, p. 170-171 apud SÉRVIO, 2014, p. 199), também defende que a cultura visual surge quando compreendemos que experimentamos o visual por meio da cultura, por meio de construções simbólicas, como "um sistema de códigos que interpõem um véu ideológico entre nós e o mundo real". É nessa linha que se pretende compreender um sistema imagético tão antigo como o dos celtas, no qual seu contexto ideológico e religioso mediava sua percepção de mundo e a sua produção de artefatos, signos e formas diversas.

Um dos métodos empregados para estudar e compreender a origem e formação de imagens dessa natureza é o iconográfico, muito utilizado na análise de imagens vinculadas à religião. "A palavra iconografia, de origem grega, por si já nos revela seu sentido: comunicarse, escrever, através da imagem. A iconografia, para que possamos apreender o que nos quer comunicar, exige do homem contemplação, silêncio, respeito, atenção" (PASTRO \& TAVARES, 2011, p. 39).

As imagens enquanto representações visuais expressam um sentido, um discurso, para além da própria linguagem. E por muito tempo a imagem propaga algo do cotidiano do sujeito, de uma comunidade ou sociedade: expressa ações, rotinas, expressa a vida, festas e ritos, além do que está fora desse cotidiano como: mitos, crenças e uma religião. Desta forma, a iconografia de imagens religiosas atua como expressão de fé, educa e ensina, colocando o sujeito na presença do Mistério. A iconografia trata a imagem a partir de duas dimensões apenas: o material, percebido pelo campo visual, o próprio signo em si (a denotação) e o imaterial, no qual a imagem cria e estimula a imaginação (a conotação), assim como os sentimentos dos receptores. Logo carrega uma mensagem denotativa clara (signos combinados) e uma mensagem conotativa (estética) interpretada de forma pessoal e subjetiva por cada indivíduo.

Contudo, a iconologia, do historiador da arte Erwin Panofsky, se torna mais cara para o referente trabalho. E se utiliza da iconografia para análise de imagens, na qualidade de arte religiosa, porém traz o conceito novo de iconologia, como terceira instância. Afirma que a "esfera em que o campo dos objetos práticos termina e o da arte começa depende da “intenção' dos seus criadores" (PANOFSKY, 1991, p.32). Para o estudo iconológico dessas intenções se deve considerar o local, momento histórico, contexto psicológico, sintético, inclinação filosófica, política e religiosa do autor, que transparece na obra. Por meio dessa metodologia, mais complexa que as análises iconográficas anteriores, Panofsky permite se reconstruir o universo religioso de uma pessoa, grupo social ou civilização, pela análise de sua produção artística ou qualquer capital simbólico deixado de legado, associado a outras fontes históricas. Ele afirma, desse modo, que o conteúdo religioso é perceptível e passível de descrição, inclusive em produções artísticas de populações antigas, como os Celtas, cuja crença espiritual não estava desvinculada do restante da vida cotidiana - como atestam estudos arqueológicos e históricos paralelos.

\section{ARTE CELTA: os símbolos e signos célticos no Escudo de Battersea}

Antes de se analisar a dita arte celta é necessário saber que os mesmos não se constituíram de um único povoado. Na realidade, o nome genérico celta é proveniente da palavra Keltoi $(K \varepsilon \lambda \tau o l)$, forma como os gregos escreveram. Tendo recebido essa pronuncia oralmente dos nativos, era um termo que incluía várias tribos de diferentes nomes, agrupadas pelas características do estilo de vida, organização política e aparência. Características essas ou "fatores, por mais gerais que sejam e facilmente mal interpretados, permaneceram da expressão 
de estranheza entre uma população e outra" (POWELL, 1958, p. 17, tradução livre). Outra questão levantada pelo pesquisador T. G. E. Powell se trata do fato de o termo celta não ter sido aplicado, pelos escritores antigos, aos habitantes da Irlanda e da Inglaterra e, também, "não há nenhuma evidência de que os nativos (insulares) tenham usado esse nome para si mesmos" (POWELL, 1958, p. 18).

Ainda segundo esse autor, trata-se de uma terminologia moderna, tanto acadêmica quanto influenciada pelo movimento Romântico do século XVIII. Atualmente, nos meios de pesquisa, se tem estudos das raízes da língua celta e dos grupos vinculados a esses troncos linguísticos, além do fato dos estudiosos sobre língua céltica do período romântico terem influenciado nesse agrupamento que vincula a parte insular britânica no conceito guarda-chuva celta (POWELL, 1958).

Dentro dessa perspectiva, os celtas hoje são apontados como sendo os povos 4 "Gálatas (Turquia), Gauleses (França, Bélgica e Itália), Hiberni ou Gaélicos (Irlanda), Britônicos (Inglaterra), Galeses (País de Gales), Escotos e Pictos (ambos da Escócia), Helvéticos (Suíça), dentre outros povos europeus" (SOUSA, 2014, p 12).

Consequentemente, o que se entende como arte celta abrangeria a todos esses povos, em diferentes períodos. Todavia, há características específicas nos artefatos escavados em determinados pontos da Europa, onde os sítios arqueológicos foram encontrados, referentes ao povo que ali habitava e ao período datado. Na descrição de Kleber Sousa:

[...] a chamada arte celta, de forma geral, refere-se à arte praticada por esses povos, a qual conheceu, dessa forma, vários períodos de desenvolvimento em diferentes pontos do território europeu, abrangendo assim uma enorme extensão de tempo, cultura e espaço geográfico (SOUSA, 2014, p. 12).

Esses vários artefatos encontrados, todavia, não deixam de ter uma proximidade de técnicas empregadas, formas e conceitos religiosos, relativo à própria similaridade, vista pelos gregos, nos povos celtas.

Não há consenso, no meio acadêmico, quanto ao período de abrangência da arte celta. Alguns afirmam que esta produção começou na arte da Idade do Bronze (3.300 A.E.C), conhecida como a cultura Hallstatt, devido ao sítio arqueológico encontrado em Hallstatt na Áustria - porém para a maioria dos estudiosos, esse se trata de um estilo pré-céltico. Outros acreditam que a produção cultural celta ocorreu entre o período da Idade do Ferro $[1.200$ A.E.C.) e o Império Romano. Por fim, há historiadores da arte que se referem apenas à arte que surge a partir da cultura La Tène, cultura da Idade do Ferro ao século I A.E.C., assim chamada por conta do sítio arqueológico de La Tène na Suíça (SOUSA, 2014).

Devido essa abrangência de povos, localidade e tempo histórico, tornou-se adequado afirmar que a arte celta possui vários estilos, divididos pelas questões geográficas e de período de ocorrência. No estilo Hallstatt, encontram-se figuras geométricas e círculos concêntricos como marca característica. O estilo La Tène, encontrado posteriormente na França e sul da Alemanha, é fruto do grande contato que os celtas dessas localidades tiveram com gregos e etruscos, absorvendo imagens zoomórficas, antropomórficas e vegetais, integradas às curvas, entrelaçados e espirais que já Ihes eram característicos. Por fim, há a chamada Arte Insular, que se desenvolveu entre os séculos VII e XI, presente na Irlanda e Grã-Bretanha, de forte influência da Roma e dos Saxões, e presente na Escócia, como herança dos pictos, gaélicos e

\footnotetext{
4 Não é proposta deste artigo esmiuçar as teorias históricas de análise dos documentos romanos e gregos que concluíram onde estavam assentadas cada uma dessas tribos celtas, que recebem hoje esses respectivos nomes.
} 
escotos que ali habitavam. Segundo Kleber Sousa, esses estilos foram divididos em duas grandes fases:

\begin{abstract}
Alguns utilizam ainda o termo "Arte celta primitiva", englobando, neste caso, a arte do século $\mathrm{V}$ a.e.c. (cultura La Tène) até meados do século II e.c. na Grã Bretanha. Tomando isso como base, podemos definir esse período como sendo uma primeira fase da arte celta. $O$ ponto mais popular, porém, nos leva a uma segunda fase: $A$ arte produzida pela Inglaterra e a Irlanda na época da alta idade média, o período mais conhecido da arte celta medieval, o que inclui ainda a arte dos pictos, da Escócia, e grandes obras, como o livro de Kells (SOUSA, 2014, p. 14).
\end{abstract}

O Escudo de Battersea, foco de análise neste artigo, pertence ao estilo La Tène e foi encontrado, em 1857, no rio Tâmisa, em Battersea, no sudoeste de Londres. Está exposto, atualmente no Museu Britânico na Inglaterra. Ele é feito em bronze, formado por vários ornamentos circulares e arabescos em $S$ - típicos do estilo celta referente ao período que foi datado - além de incrustado com discos de vidro vermelhos. Os celtas usavam frequentemente o bronze revestido com esmalte para fazer seus escudos e armaduras, decorado com espirais dispostas simetricamente.

Esse escudo encontrado é uma obra clássica da metalurgia celta e é, na verdade, a superfície exterior de outro escudo feito provavelmente de madeira. Feito com a técnica da fundição, da modelagem de metal - através de batidas de martelo - e da extrusão, que se constituí em uma técnica na qual se força a passagem do metal através de um orifício, que lhe dava uma forma alongada, possibilitando o entrelaçamento desses fios de metal, para a produção das formas circulares entrelaçadas.

O local onde foi encontrado sugere que o escudo foi atirado ao mar como uma oferenda aos Deuses. Acredita-se, também, que foi utilizado em cerimônias rituais antes do combate. $\bigcirc$ padrão encontrado nesse escudo reflete, ainda, a cosmovisão céltica, bem como outros simbolismos religiosos, que serão analisados ao longo deste artigo. Eis uma imagem: 


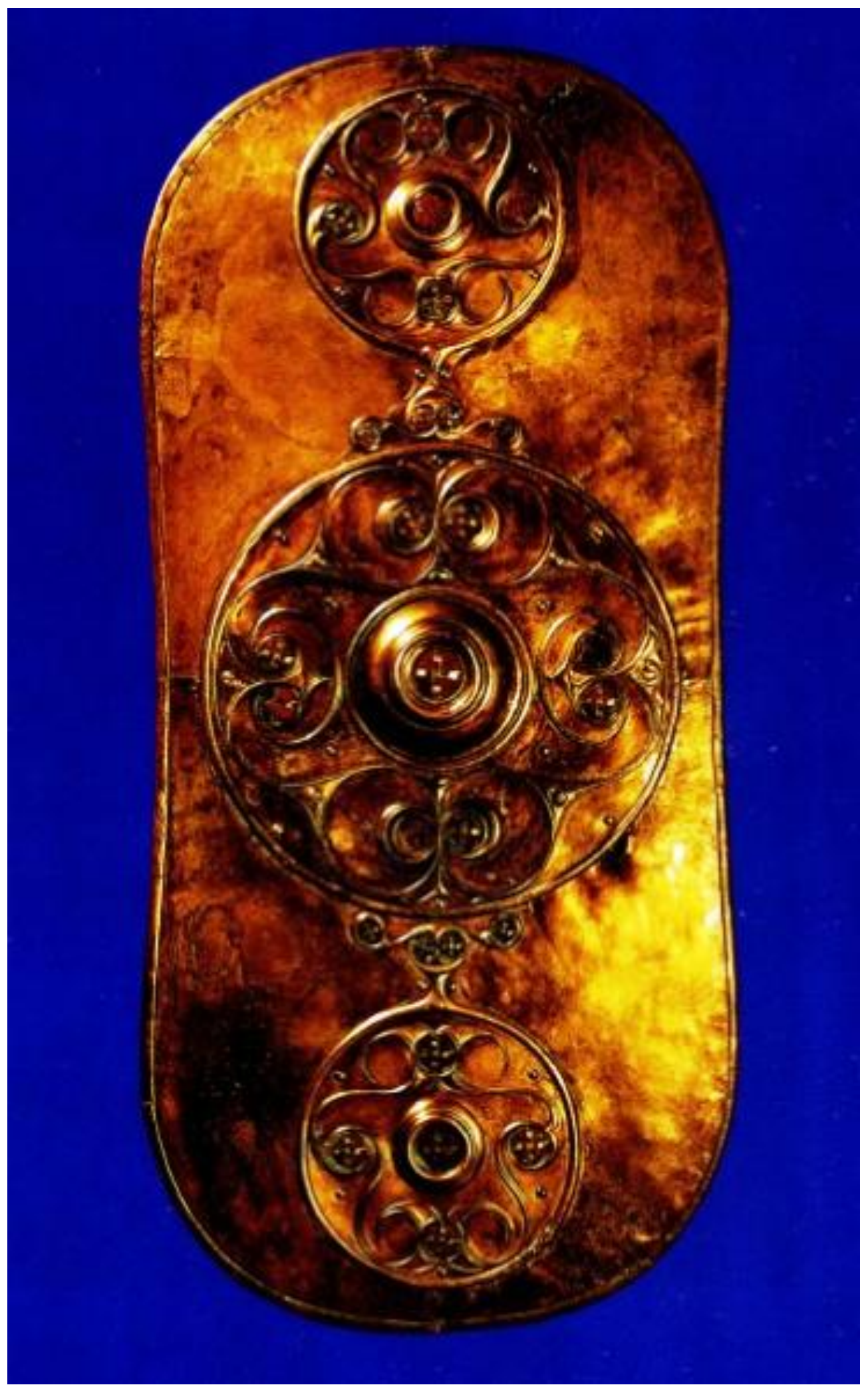

Figura 1- Escudo de Battersea (400 - 200 BC, Dimensão: 35 x 77 cm) 5 .

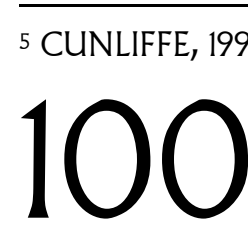




\section{ESTILO CELTA E PANOFSKY}

A abordagem de Erwin Panofsky acerca do estudo das humanitas trata da natureza do ser humano que, apesar de se pretender livre, precisa de parâmetros e saberes norteadores que encontra na própria trajetória humana. Esse discurso leva o autor a definir que "o humanista, portanto, rejeita a autoridade; mas respeita a tradição" (PANOFSKY, 1991, p. 22). A tradição são os conhecimentos deixados por seus antepassados, que precisam ser estudados e levados em conta como um guia, que ensinam o discernimento ao ser humano. Sem esse legado a humanidade não teria sentido sobre si mesma. Nas palavras de Panofsky:

O homem é, na verdade, o único animal que deixa registros atrás de si, pois é o único animal cujos produtos "chamam à mente" uma ideia que se distingue da existência material destes (PANOFSKY, 1991, p. 23).

O que Panofsky menciona no texto acima remete à definição de ciências humanas, que segundo o autor, interessa-se pelos registros humanos, que se constitui no arcabouço de signos, deixados pelos grupos humanos do passado, repletos de relações de significação e de conceitos. Referente ao que é acessível aos sentidos a partir da natureza, os seres humanos produzem construções de todo tipo e são capazes de representar as ideias e conceitos por traz dessas estruturas. O humanista, segundo Panofsky, seleciona uma variedade de registros humanos delineando o que se denomina cosmo da cultura e considerava a história da arte como parte essencial do estudo da chamada humanitas. Pois, através da interpretação das obras artísticas, se revela a história do espírito humano.

Os escudos, armaduras, armas, capacetes de guerra, torques, jóias e outros utensílios encontrados da vida cotidiana dos celtas possuíam ornamentos complexos em metal, às vezes em vidro, com formas torneadas e complexas. Esse arcabouço de produções, logo virou interesse de arqueólogos, como Sally M. Foster e Dennis William Harding, de historiadores, estudiosos da religião e, também, historiadores da arte como a artista e designer Lora S. Irish. Percebeu-se que não se tratavam apenas de objetos práticos comuns, pois havia uma grande preocupação com as formas e significação nessas produções. Como afirma Erwin Panofsky, "um historiador da arte, por tanto, é um humanista cujo material primário consiste nos registros que nos chegam sob a forma de obras de arte" (PANOFSKY, 1991, p. 30). Nesse contexto, sua abordagem sobre as formas e intenções na arte se torna útil na análise à chamada arte celta (Conferir figuras 2 e 3).

Ele afirma que "numa obra de arte, o interesse na ideia é equilibrado e pode até ser eclipsado por um interesse na forma" (PANOFSKY, 1991, p. 31-32). A definição básica, segundo o autor, de obra de arte é que esta deve ser experimentada esteticamente, ou seja, sempre tem significação estética. Quaisquer artefatos que não tenham um sentido estético são tidos como puramente práticos que são, na maioria das vezes, veículos de comunicação e ferramentas ou aparelhos. Todavia, se bem observado, a maioria das obras de arte também atende esses dois fins. Uma ferramenta prática ou veículo de comunicação, quanto mais desloca o seu interesse para a forma em que se apresenta - no design do aparelho, ou na caligrafia de uma carta, ou na utilização de um poema para transmissão de uma mensagem - mais ela se aproxima de uma obra de arte. É nítida a preocupação com as formas encontrada nos artefatos exemplificados nas figuras acima. Como observado, os padrões circulares e espiralados se repetem no escudo, nas joias, utensílios, pinturas e em quase todas as manifestações artísticas célticas (Conferir Figura 4). 
A espiritualidade da arte celta

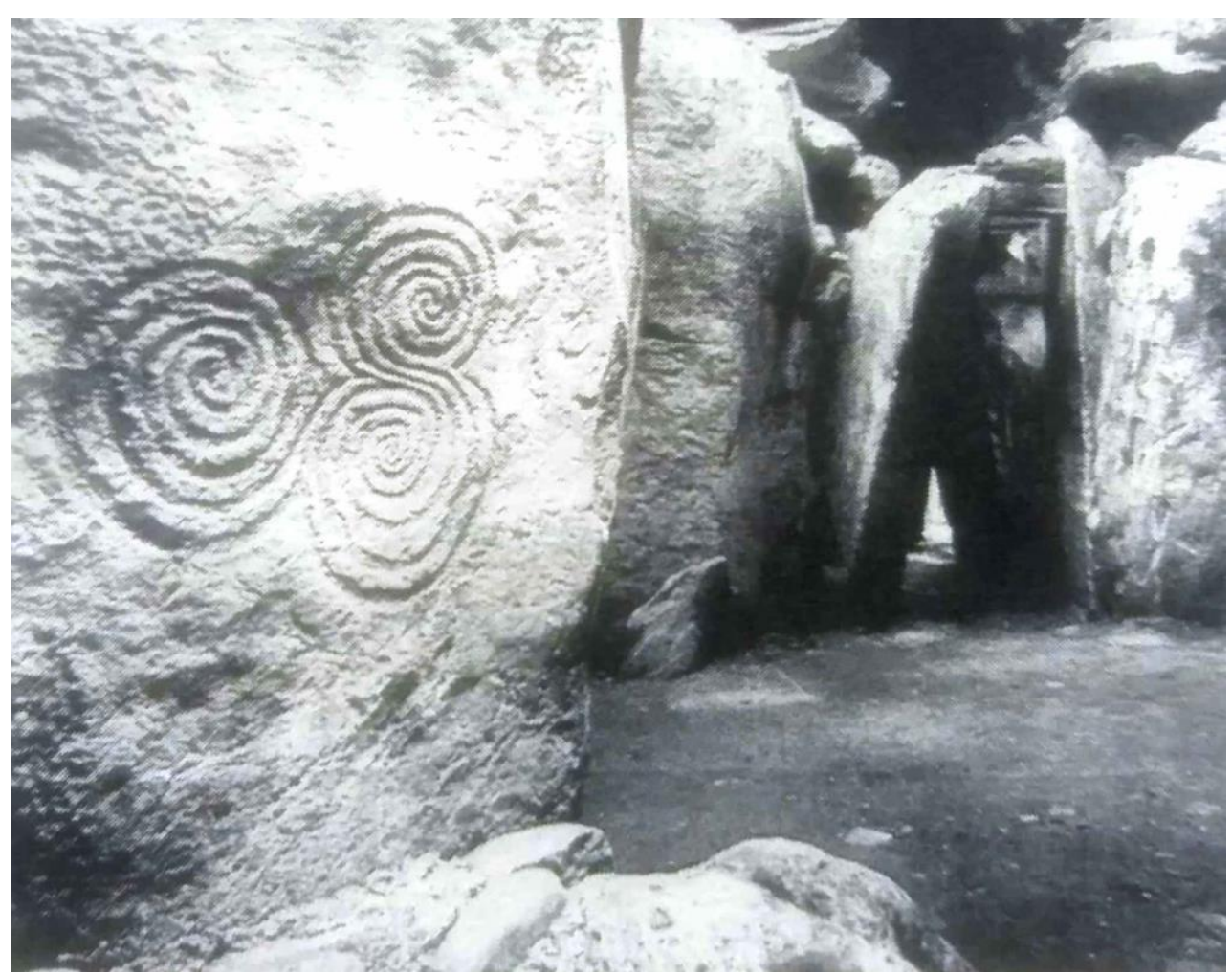

Figura 2 - Triskle de Newgrange (Irlanda), no monumento Brú na Bóinneb.

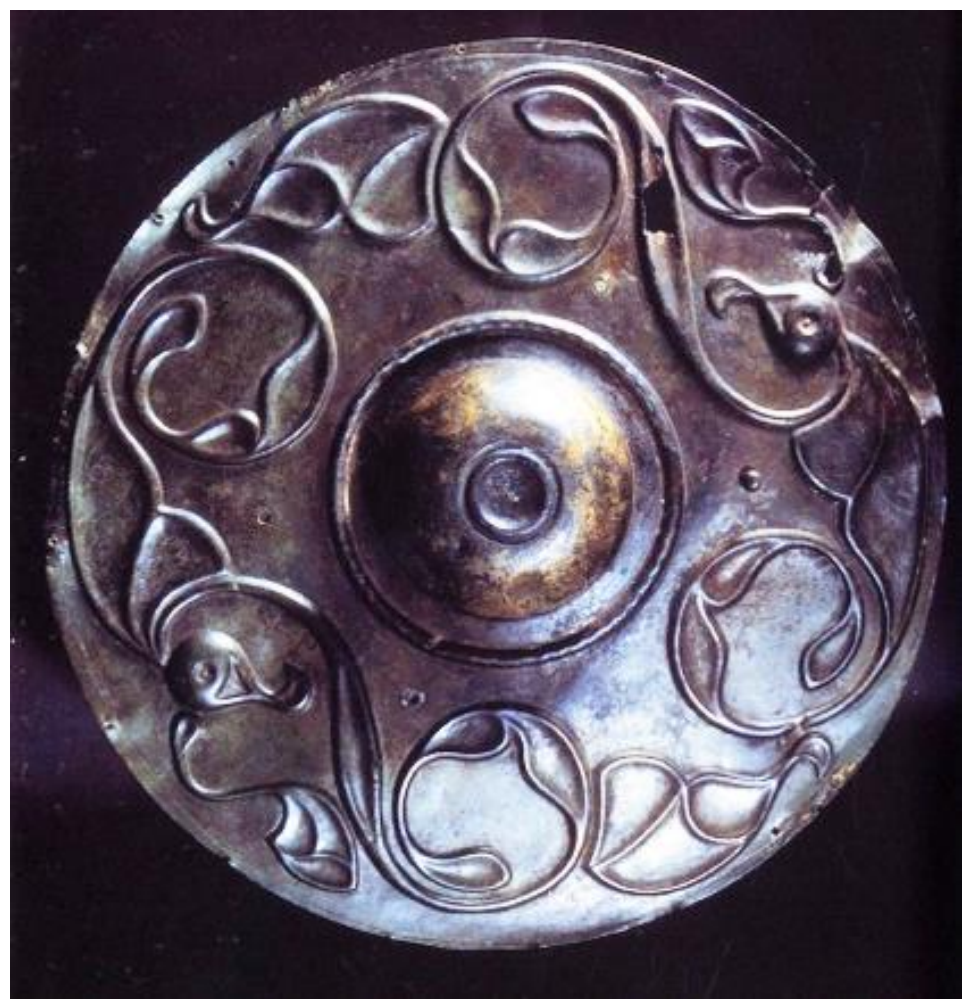

Figura 3- Escudo de bronze

6 QUINTINO, 2000, p. 64. 


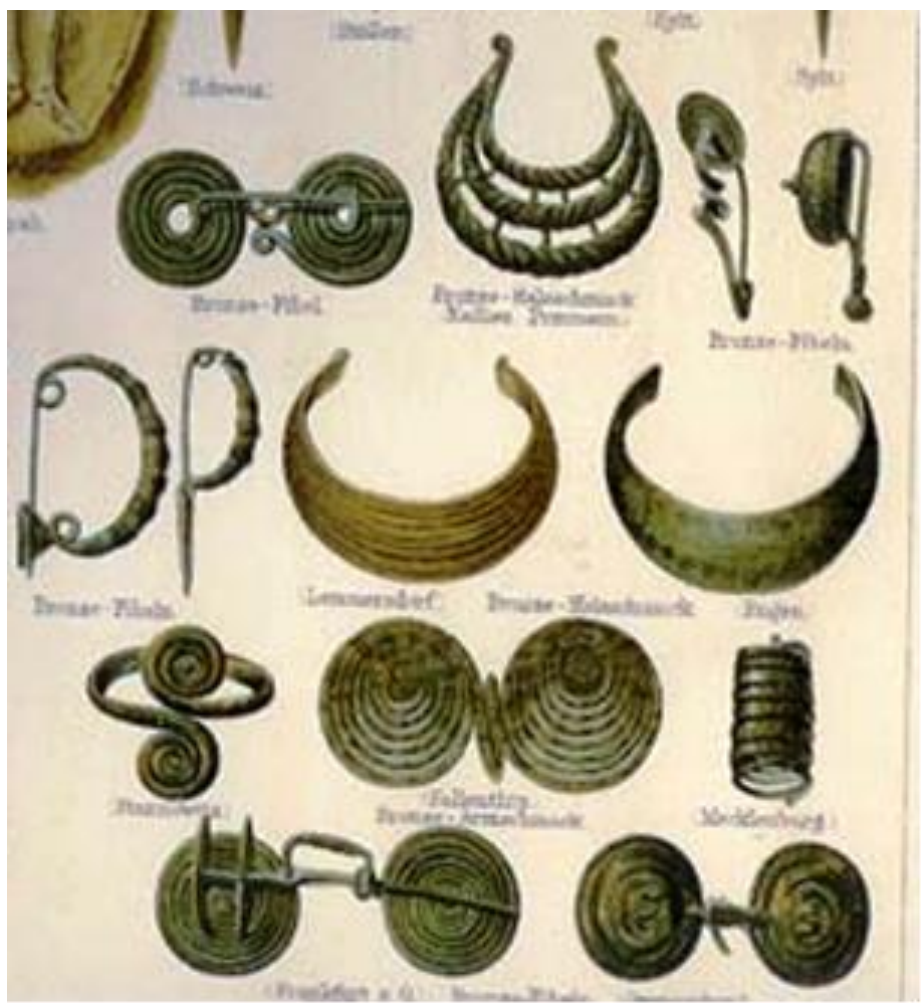

Figura 4- Artefatos com espirais Hallstatt

Não é possível definir o momento exato dessa transição entre o utensílio prático e sua transformação em uma obra de arte. Quando o domínio do campo prático do objeto termina e o da arte começa depende da intenção de quem o produz. Essas intenções, segundo o historiador da arte, são condicionadas pela época e o meio em que vivem. Vários artefatos como os castiçais de Milão, os túmulos de Lorenzo e Giuliano de Medici - esculpidos por Michelangelo - até os escudos ornamentados de antigos heróis, são exemplos desse tipo de, já consideradas hoje, obras de arte (PANOFSKY, 1991). Em suas próprias palavras, "vimos todos, com nossos próprios olhos, os utensílios e fetiches das tribos africanas serem transferidos dos museus de etnologia para as exposições de arte" (PANOFSKY, 1991, p. 33).

Dessa forma, pode-se entender o porquê do termo arte celta ter se tornado um termo adequado; as teorias sobre arte mudaram bastante ao longo da sua história. A arqueologia que tem encontrado esses artefatos da arte celta - requer uma análise racional, na qual precisa de usos de raios- $\mathbf{X}$, macrofotografias, etc., para se detectar materiais usados, período de criação, possíveis partes ocultas, entre outras informações importantes. Todavia precisa ser complementada com uma análise subjetiva, que necessita que se interprete estilisticamente o artefato em questão. A recriação estética intuitiva reconstruirá as intenções e o universo da obra. Nesse trabalho subjetivo, o autor explica que o humanista dedica-se a um processo mental sintético. Precisa reconstruir e recriar as ações e criações mentalmente, para encontrar as concepções artísticas de uma estátua ou artefato, na medida em que essas têm um significado (PANOFSKY, 1991).

7 CUNLIFFE, 1999, p. 197.

8 Disponível em:<http://www.claudiocrow.com.br/celtas-heranca-arte.htm> Acesso em julho. 2017. 
Panofsky explana bem como o trabalho do historiador da arte se constitui em instruirse o máximo possível sobre as circunstâncias em que foram criados esses achados artísticos, que são objeto de seu estudo. Deve verificar toda informação existente acerca do meio, idade, autoria, destino, etc; deve fazer comparações com outras obras/produções de mesma classe, período e proximidade de território; analisar documentos que reflitam padrões estéticos de um lugar ou da época; bem como deve ler livros de teologia e mitologia do período para poder realmente identificar o assunto tratado. Essa atitude básica, de seu método, dará a possibilidade de se encontrara nação, período, classe, crença filosófica ou religiosa presente e concentrada, às vezes inconscientemente, em uma obra. Em seus termos, "a intenção acha-se definitivamente fixada na ideia da obra" (PANOFSKY, 1991, p. 31). É o que ocorre ao se analisar o Escudo de Battersea. Os ornamentos circulares também são o ponto central do escudo. As volutas entrelaçadas e simétricas, além do fato de todo o escudo ter formas arredondada, dá a entender que a forma do círculo é de extrema importância na arte celta. Kleber Sousa, em sua análise sobre arte céltica, explica:

Como padrão, a arte celta evita linhas retas e é basicamente ornamental, por vezes, simétrica. Porém, em determinados trabalhos através do tempo, se baseou em outros estilos, como o da arte escandinava, mostrando influência de muitas culturas em seus ornamentos, como nós, figuras humanas, espirais, figuras zoomórficas, letras, padrões e ornamentos com formato de plantas (SOUSA, 2014, p. 14).

Essa predominância de formas circulares, evitando ao máximo se representar algo em linhas retas, deriva da própria cosmovisão celta. Um dos significados atuais atribuído aos nós, formas circulares e entrelaçadas, é a ideia do infinito e da ciclicidade, onde os caminhos se cruzam e retornam ao início. Claudio Crow Quintino, pesquisador e autor brasileiro sobre os povos celtas, afirma:

O mesmo ocorre com a noção de tempo celta: os celtas não compreendiam o tempo como uma sucessão de eventos lineares, como a humanidade define hoje. Na verdade, segundo a ótica celta, passado, presente e futuro se misturam e se entrelaçam [...] (QUINTINO, 2000, p. 42).

Os celtas baseavam sua crença no ciclo das estações, do sol e da lua e todo caráter cíclico da vida vegetal e da natureza como um todo, que na sua cosmovisão refletia a própria vida humana, que morre e sempre renasce. Muitos monumentos foram encontrados onde os celtas habitavam como esculturas em pedra de touros, porcos e outros animais e achavam-se situadas em cercados para o gado e o cultivo. Powell $(1958$, p. 146) afirma que estas esculturas são provavelmente de origem mediterrânica, mas seu propósito religioso serviu aos Celtas, que as utilizaram para culto de fertilidade e prosperidade dos rebanhos, da colheita e da vida. Quintino (2000, p. 53) afirma também que "os celtas (como outros povos antigos) enxergavam na fertilidade da terra e nos ciclos da natureza algo de divino, e faziam de tudo para integra-se a essa natureza".

Nessa crença de integração e de similaridade entre a vida humana e os ciclos naturais, os próprios "bosques sagrados, ou extensão de terreno em que cresciam tufos de árvores" (POWELL, 1958, p. 138) eram seus templos de culto e religiosidade e a presença da ideia do 
fluxo contínuo de transformação da vida vegetal e eterno retorno ao início, levava a crença da própria reencarnação - eterno retorno ao ciclo da vida - largamente simbolizados no seu padrão artístico circular espiralado. Juliette Wood, especialista em folclore e literatura celta, declara em seu livro:

A poesia e narrativa celtas contêm numerosas referências ao ciclo da vida, morte e pós-morte. Os artistas e escritores celtas usavam essa visão em suas representações do cosmo como um eterno nó de experiência, simbolizado pelos padrões sem fim entrelaçados [...] (WOOD, 2011, p. 131).

A produção de um artefato de qualquer natureza, do mesmo modo, tinha, para eles, uma inspiração ligada a sua religiosidade, por isso a necessidade de representar os ciclos da vida nas próprias armaduras, escudos e utensílios práticos e decorativos.

A influência de outros povos, ressaltada por Kleber Sousa (2014) em seu trabalho, como os escandinavos, os etruscos, dentre outros, fez com que os celtas absorvessem formas humanas, de animais e plantas às volutas, gavinhas e formas espiraladas que já eram características em sua produção artística. Plantas e animais entrelaçados reforçavam a ligação que tinham com a natureza, porém essas figuras receberam deformações, se tornando corpos curvados e também entrelaçados, pois à ligação com os ciclos da vida e reencarnação mostram ter sido preponderante em suas crenças religiosas (Conforme as Figuras 5, 6, 7 e 8).

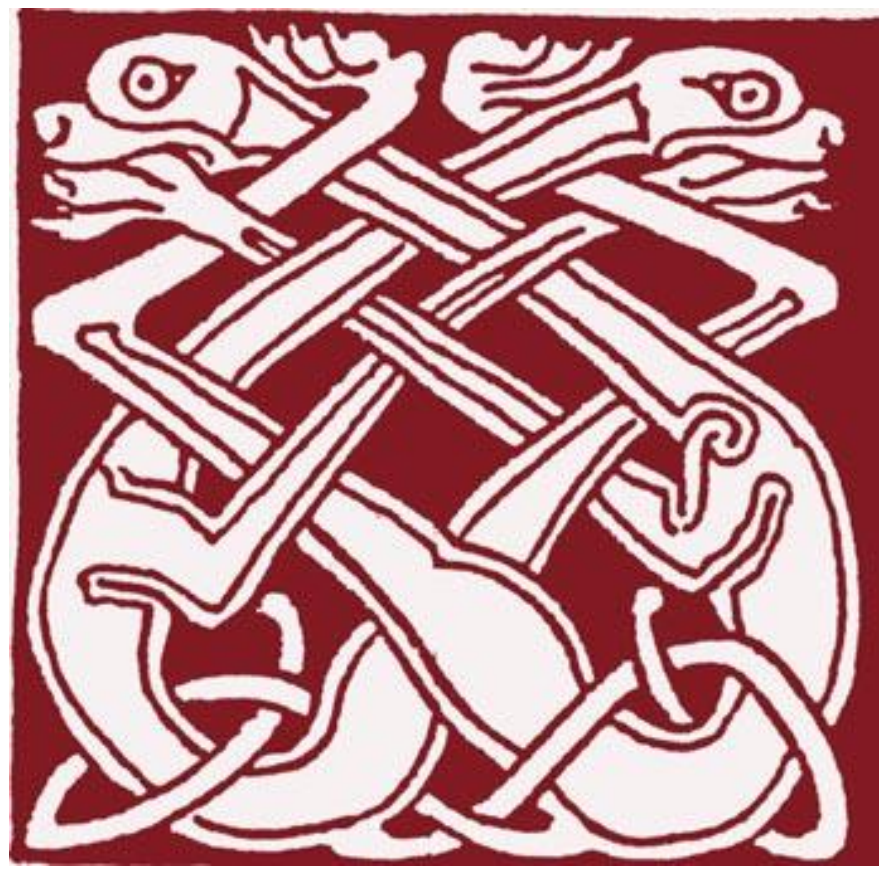

Figura 5 - Entrelaçado medieval celta ${ }^{9}$

9Disponível em:<http:/ / www.claudiocrow.com.br/celtas-heranca-arte.htm> Acesso em julho. 2017. 


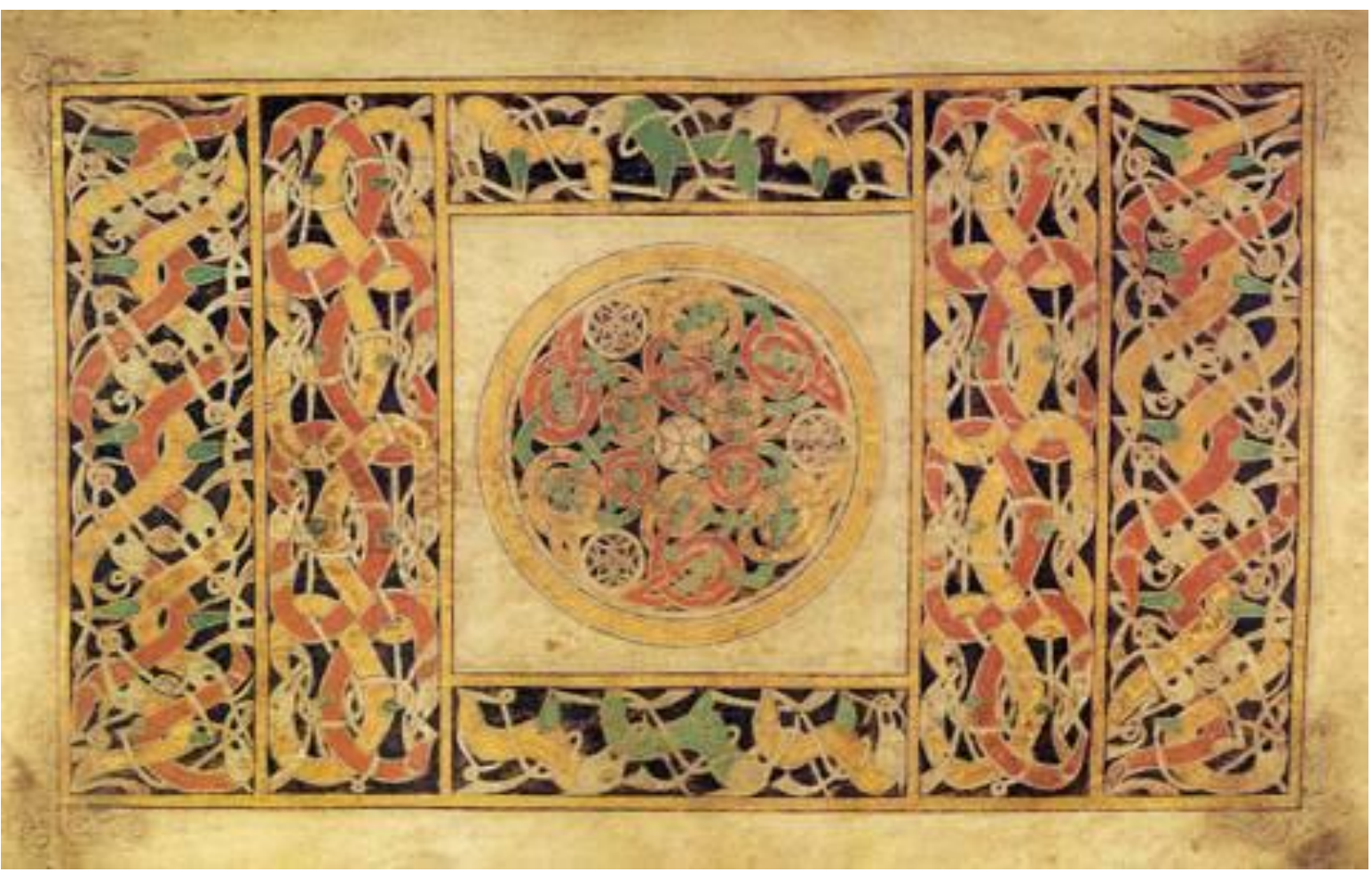

Figura 6- Capa de papiro medievallo

10 Disponível em: <https:/ / finds.org.uk/staffshoardsymposium/papers/georgeandisabelhenderson > Acesso em março. 2018. 
A espiritualidade da arte celta

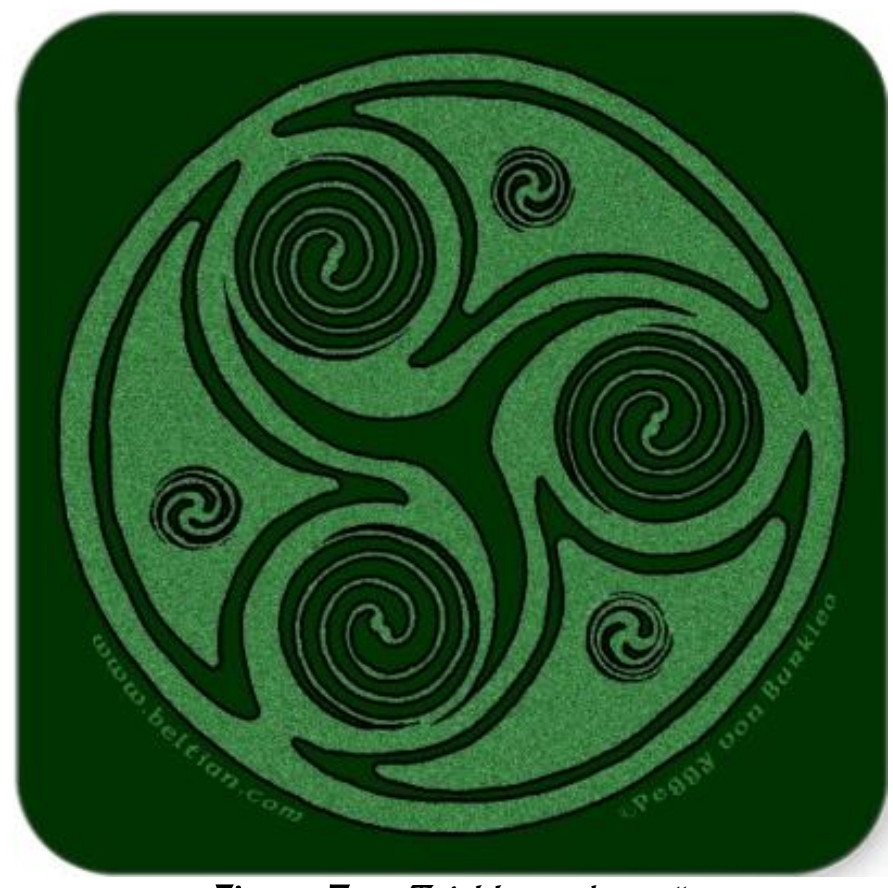

Figura 7 - Triskle modernoll

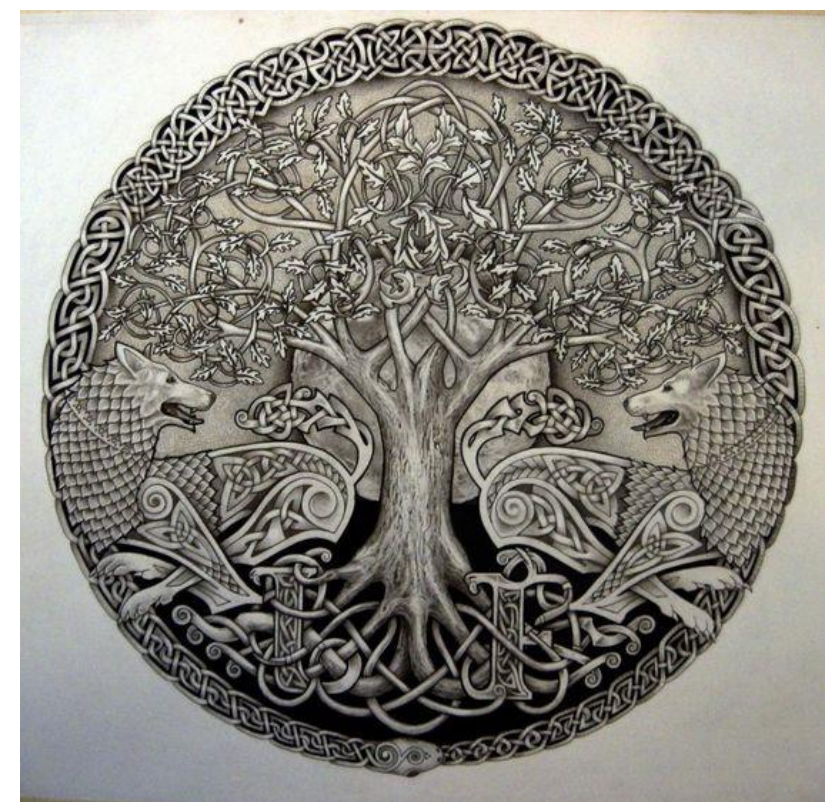

Figura 8- Arvore celta baseada em nós medievais'2

11 Disponível em: <https://www.zazzle.com.br/etiqueta_celta_da_arte_triskel_2_espiral-217742528778250435> Acesso em julho. 2017.

12 Disponível em: <https://br.pinterest.com/pin/325525879301181278/> Acesso em março. 2018. 
Mesmo com essas influências, algo da essência celta permaneceu na adaptação que fizeram das técnicas importadas, que se eternizaram como seu estilo próprio:

[...] apesar das diversas transformações estilísticas que foram experimentadas através dos séculos, a arte celta por fim conseguiu definir um estilo coerente e harmônico, mantendo seu foco em temas estilizados e com decorações geométricas, e assim tornou bastante característico seu uso de formas circulares, espirais e triskles (SOUSA, 2014, p. 15).

Assim, acabaram por criar essa unidade de estilo, pois ela reverbera sua cosmovisão religiosa. Panofsky afirma que, para o humanista, ou seja, o estudioso dos registros humanos nesse caso, o historiador da arte - as obras emergem de uma corrente de tempo, porém não envelhecem. Elas refletem todo o universo cultural da época que foram produzidas, todavia têm um significado autônomo. Esses significados influenciam na criação de conceito gerais da história. "O cosmo da cultura, como o cosmo da natureza, é uma estrutura espaço-temporal", (PANOFSKY, 1991, p. 26), na qual deve ser possível relacionar seus elementos (registros) dentro de um quadro de referência. No caso dos celtas, o quadro de referência que deu origem a classificação de seu estilo artístico está baseado na sua concepção espiritual de mundo e vida. A compreensão do estilo celta está indissociado do entendimento acerca da religiosidade desse povo. Como o próprio autor em questão afirmou, o "historiador da arte denomina de estrutura estilística das obras aquilo que, no objeto, provém de uma experiência interior" (PANOFSKY, 1991, p. 40).

Esse profissional da arte, que estuda uma obra, precisa analisar outros documentos e fontes que foram produzidos no mesmo período e durante o processo no qual as obras foram realizadas. Sem essa atitude, não seria possível avaliar o conteúdo e a intenção de quem produziu a obra, artefato, ou qualquer outro registro artístico deixado por um povo. Esse processo dá origem aos conceitos genéricos de uma época artística, um estilo, intenção religiosa, etc. $\bigcirc$ interessante é que a análise de registros humanos cria categorias históricas, porém os primeiros só podem ser interpretados em função dos segundos, criando o que o autor chama de situação orgânica, explanado por ele da seguinte maneira:

É verdade que os monumentos e documentos individuais só podem ser examinados, interpretados e classificados à luz de um conceito histórico geral, ao mesmo tempo que só se pode erigir esse conceito histórico geral com base em monumentos e documentos individuais. [...] Essa situação, no entanto, não é, de jeito algum, um beco sem saída (PANOFSKY, 1991, p. 28-29).

Cada novo achado da arqueologia, ou nova documentação, enriquecerá as categorias gerais que já existam, ou trará novos elementos que refutem alguns conceitos gerais e criem novos. No entanto, o autor afirma, "no exame dos registros cumpre decodificá-los e interpretá-los, sendo classificados e coordenados num sistema coerente" (PANOFSKY, 1991, p. 26). O padrão da arte celta atende esse sistema coerente na medida em que, além de mostrar certa unidade das formas e proximidade religiosa entre os vários povos indo-europeus considerados célticos, os padrões encontrados em sua arte refletem suas narrativas míticas e seus rituais, ou festivais, de ciclicidade da vida humana e de toda natureza.

\section{8}


Muito dos mitos celtas, estruturas de rituais, costumes, festivais sazonais, entre outros foram deixados em forma de registro pelos romanos e por padres irlandeses, recém convertidos, que sentiram necessidade de escrever a sabedoria local de sua terra, mesmo que adeptos da nova religião. Claudio Quintino relata que:

Ele [Júlio César] lutou arduamente contra a resistência gaulesa e, em suas crônicas de guerra (De Bello Gallico), registrou muito dos costumes e da cultura dos celtas da Gália. Depois disso, a preservação dos mitos, lendas e religião dos celtas coube aos monges cristãos que paradoxalmente visavam suplantar a religião nativa com a religião nova [...] (QUINTINO, 2000, p. 50).

Segundo esse autor, apesar de comporem vários fragmentos de registros - tanto arqueológico como os documentos escritos - acerca da religiosidade celta, "compõe um mosaico fiel da religião dos antigos celtas" (QUINTINO, 2000, p. 50). De posse das narrativas míticas, costumes de sepultamento, crenças pós-morte, panteão de Deuses, comportamento bélico, entre outras características dos povos celtas, foi então possível se analisar o conteúdo dos achados arqueológicos. Porém, reside a pergunta, ou será que a análise desses achados é que possibilitou se compreender a cosmovisão desse povo nos outros documentos? Segundo a metodologia de Erwin Panofsky, os dois sentidos de análise ocorreram e se complementam em um ciclo fechado.

A síntese recriativa - a partir da avaliação de todos os tipos de escritos da época, inclusive os religiosos - e a pesquisa arqueológica estão interligadas de modo a formar o que já se chamou de situação orgânica. Uma serve de base para a investigação da outra e ambas se qualificam e retificam mutuamente. $O$ conjunto de toda essa análise é formado por três componentes: forma material, ideia (ou seja, tema) e conteúdo. Nesse momento é que aparecem as definições de Panofsky acerca da diferença entre a iconografia e iconologia. A área de atuação da iconografia é a descrição quantitativa - a forma - e a classificação do temas e assuntos presentes na obra. A iconologia, por sua vez, atua sobre interpretação do significado intrínseco ou conteúdo da obra, no intuito de reconstituir o capital de valores simbólicos.

Nessa perspectiva, o autor divide a obra em três camadas de significação e análise: 1) o significado primário ou natural, no qual são descritas as formas, cores e linhas e a relação entre elas, trata-se da análise pré-iconografia, na qual a própria experiência pessoal do intérprete influência, com algumas correções histórias a fim de se detectar o estilo (realista ou irrealista, por exemplo); 2) o significado secundário ou convencional, que leva em conta os motivos artísticos ou temas, na qual busca analisar as imagens, estórias e alegorias, tratando-se da análise iconográfica propriamente dita, que requer o conhecimento das fontes literárias, a familiaridade com temas específicos de determinadas condições históricas e relaciona a imagem, ou alegoria, com a tradição iconográfica da época; 3) o significado intrínseco ou conteúdo, que trata do mundo de valores simbólicos, convicções religiosas e filosóficas, condensados na obra em um grau mais profundo, que um artista ou povo pode ter deixado como marca em seus registros. Trata-se da análise iconológica, que geralmente usa metodologias históricas, psicológicas, críticas, entre outras, sendo um método que utiliza a diversidade das análises iconográficas e mais, constituindo a intuição sintética - ou a recriação estética intuitiva - já mencionada. Exige a familiaridade com as tendências essenciais do espírito humano, sintomas culturais ou símbolos em geral. Os elementos analisados são condicionados pelo psiquismo e a

\section{9}


visão de mundo pessoal ou coletiva, representados por meio de objetos e eventos em determinadas condições históricas (PANOFSKY, 1991).

Para arte celta, a forma ou significado primário seria o material de que é feito, cores, a estrutura dos ornamentos, escolha por forma circulares, etc. Os celtas utilizavam muito bronze e ouro em seus artefatos, além de coral vermelho e o âmbar, sendo esses últimos materiais encontrados em outras regiões bem distantes da Europa. Devido à natureza desses materiais, as obras celtas puderam ser hoje estudadas, pois quase não houve desgaste e a utilização deles se dava para além de finalidades práticas. Grandes estudiosos dos artefatos celtas explicam que:

Para os celtas, o ouro era mais do que apenas jóias e suntuosidade - o nobre metal com seu eterno brilho e pouco suscetível à corrosão era sinônimo de imortalidade. Por essa razão, eles produziram enfeites e objetos do mais elevado poder simbólico (RADEMACHER, PAETSCH, 2012, p. 40, apud SOUSA, 2014, p. 15).

A apreciação de metais preciosos e o esforço que faziam para consegui-los eram também, muito provavelmente, pela empreitada religiosa e o valor espiritual que isso significaria na utilização do artefato feito desse material. A ideia ou significado secundário seria a ciclicidade da vida, os ciclos da natureza e a reencarnação, como já visto, devido às formas circulares, entrelaçadas e simétricas. $O$ conteúdo ou significado intrínseco, por sua vez, seria a arte bélica religiosa, que era muito presente entre os celtas e tinha pano de fundo religioso, nas palavras de Kleber:

A arte bélica também foi um dos principais pontos para o desenvolvimento artístico dos celtas. Graças à grande importância dada às castas guerreira e sacerdotal, seu uso ia muito além do funcional, servindo às vezes como forma de honrar os guerreiros mortos, e outras vezes como talismãs ou oferendas para os Deuses (SOUSA, 2014, p. 15).

A maior parte da produção artística celta é formada pela arte bélica. Os celtas eram um povo de ideal guerreiro, no qual homens e mulheres treinavam e iam para campos de batalha. Como ressalta Barry Cunliffe, "a aristocracia guerreira frequentemente enterrava seus mortos com suas lanças e espadas" e nesses túmulos que foram encontradas "o estilo mais altamente sofisticado da arte celta" (1999, p. 63, tradução livre). Obviamente era de extrema importância proteger seu território da invasão de clãs inimigos e, como já explanado acima, todas as atividades da vida cotidiana estavam imbricadas com concepções religiosas nesse período, a guerra não estaria de fora. Existe uma gama de Deuses dos panteões celtas ligados à proteção e a guerra. O culto aos ancestrais mortos também era uma forte característica de sua espiritualidade e aos mortos em batalha havia ainda mais prestígio e honra.

O escudo de Battersea reúne todos esses elementos acima citados e foi encontrado na água, mas precisamente no rio Tâmisa, e na cosmovisão celta as águas eram portal para o Outro Mundo ou o mundo dos mortos, onde seus ancestrais repousavam após a morte antes do clico da próxima encarnação. Na explanação de Juliette Wood sobre o pensamento celta:

A água, na qual existem tantos reinos misteriosos, é um símbolo apropriado da verdade que existe sob a superfície das coisas - um tipo de véu translúcido, às vezes transparente às vezes opaco, entre este

\section{0}


mundo e os mundos do pós-morte. Por meio do poder mágico da água, podemos entrar em contato com a sabedoria do Outro Mundo (WOOD, 2011, p. 74).

Ainda acerca da religiosidade celta em relação às águas, o estudioso E. T. G. Powell analisa os relatos do historiador grego Possidônio:

A referência de Possidônio a lagoas sagradas, o que também pode significar charcos ou pântanos, tem um particular interesse devido a certo número de descobertas arqueológicas para as quais não há melhor interpretação que como depósitos votivos (POWELL, 1958, p. 147).

Esses depósitos são assim chamados por serem locais sagrados de oferendas rituais. $\bigcirc$ escudo depositado no rio se constituiu, então, em uma oferenda aos ancestrais pela proteção e ajuda na vitória após uma batalha. Mesmo com a perda das vidas na batalha em questão - ou até se perdessem a batalha - os celtas acreditavam que sempre voltariam à vida, ou seja, a morte nunca era o fim. Morrer em batalha era uma honra e nunca significava uma derrota propriamente dita.

Outras hipóteses também são levantadas acerca do escudo de Battersea. Provavelmente foi usado em cerimônia antes da batalha, pois sempre se preparavam para a guerra com pinturas rituais pelo corpo, pedindo auxílio e proteção aos Deuses e ancestrais. Acreditavam, também, que esses espíritos de ancestrais poderiam habitar o escudo e durante a batalha lhes concederia proteção e vitória.

Percebe-se, assim, que devido ao fato de quase todas as atividades desse grupo humano ser permeado pela sua convicção religiosa, nos três níveis de análise (pré-iconográfico, iconográfico e iconológico) do artefato em questão, as intenções religiosas foram determinantes para a escolha do material, da forma, alegoria e uso - tanto ritual, quanto prático (no caso, a guerra) - como em seu conteúdo intrínseco permeado de crenças e narrativas mitológicas. Esse trabalho interpretativo que, segundo Panofsky, é a iconologia se trata a história da arte propriamente dita. A forma da obra de arte é de suma importância, porém esse estudo da arte se ocupa mais do conteúdo das obras, ligadas às intenções de quem a produziu, a partir de sua cosmovisão, concepções religiosas e filosóficas, que enriquecem grandemente o estudo da história humana como um todo.

\section{CONSIDERAÇÕES FINAIS}

O artefato celta em questão, o escudo de Battersea, é um objeto prático, artístico pois é estético, ou seja, tem preocupação com a forma - e é, também, religioso. Na verdade, a intenção estética dele, presente nas espirais e volutas ornamentadas com discos de vidro e anéis de metal, foi assim projetada devido à concepção religiosa desse povo. Nesse estágio da vida humana, o que se apresenta é o fato de que não existia uma distinção clara do que era propriamente religioso, ou era um objeto profano, o que era arte ou era religião, as atividades se encontravam imbricadas numa mesma forma de viver e de ser dessa sociedade.

Nesse contexto, a cultura visual na dimensão artística, mais especificamente a arte religiosa, contribui à compreensão da trajetória do próprio pensamento humano, das suas crenças e comportamentos sociais provenientes dessas crenças, ao se analisar os artefatos religiosos produzidos por diversas civilizações no decorrer do tempo. Os símbolos, imagens, 
pinturas e artefatos da vida prática, criadas por povos antigos fornecem grande material que faz parte de uma visualidade cultural do período histórico em questão. Existia um pano de fundo religioso entre os celtas que os faziam enxergar na ciclicidade da natureza (das estações, dos astros, etc) o entendimento e significação para todas as outras ordens naturais, espirituais e sociais. Ou em sentido oposto, a observância desses eventos pode ter dado origem a seus conceitos religiosos e míticos de ciclicidade, dos quais se formou seu horizonte cultural mediador das experiências visuais diversas, sendo elas: tanto as práticas do cotidiano, como a guerra, as colheitas e os ritos de passagem; quanto as práticas de criação imagética, como seus símbolos, artefatos, escudos, signos, pinturas, entre outras. Na verdade, os dois sentidos se complementam, formando o panorama e significados da cultura religiosa (e visual) celta, atestada em suas canções, poemas e narrativas míticas.

O resultado deste estudo mostra que técnicas empregadas por diversos estudos atuais, para sociedades contemporâneas e sociedades antigas que possuíam linguagem escrita, podem lançar uma luz para se estudar, também, antigos modelos sociais, sua religiosidade e sua, como já mencionada, visualidade cultural. A abordagem da iconologia de Erwin Panofsky é de grande valia para se analisar o conteúdo religioso e todo universo de crenças de uma antiga civilização ou povoado a partir de suas obras artísticas - que hoje são consideradas como tal devido ao alargamento do conceito de arte e estilos artísticos. A riqueza dos achados arqueológicos de povoados dessa natureza é de grande importância e pode fomentar novas abordagens para o estudo da história, das religiões, da história comparadas das religiões e, espacialmente, da história da arte. Contribuindo para o aumento do horizonte de percepção da arte como a externalização do que é próprio do espírito humano.

\section{Referências}

CUNLIFFE, Barry. The ancient Celts. Oxford: Penguin, 1999. 324p.

HIGUET, Etienne. Imagens e Imaginário: subsídios teórico-metodológicos para interpretação das imagens simbólicas e religiosas. In: NOGUEIRA, P.A.S. (org.) Religião e Linguagem: abordagens teóricas interdisciplinares. São Paulo: Paulus, 2015, p. 15-62.

OTTO, Rudolf. O sagrado. os aspectos irracionais na noção do divino e sua relação com o racional. Traduzido por O. Schlupp. São Leopoldo: sinodal/ EST; Petrópolis: Vozes, 2007.

PANOFSKY, Erwin. Significado nas Artes Visuais. São Paulo: Editora Perspectiva, 1991.

PASTRO, Claúdio; TAVARES, André. Iconografia como expressão da fé. Cap. 3, p. 38-49. (In): (Org.) MARIANI, Ceci Baptista; VILHENA, Maria Ângelo. Teologia e Arte: expressão de transcendência, caminhos de renovação. São Paulo: Paulinas, 2011.

POWELL, T. G. E. The Celts. London: Thames and Hudson, 1958. 232p.

QUINTINO, Claudio Crow. A Religião da Grande Deusa - raízes históricas e sementes filosóficas. São Paulo: Editora Gaia, 2000.

SÉRVIO, Pablo Petit Passos. O que estudam os estudos de cultura visual? Revista Digital do LAV - Santa Maria - vol. 7, n.2, p. 196-215 - mai./ ago. 2014. 
SOUSA, Kleber Ribeiro de. ARTE CELTA: A influência celta na contemporaneidade. 2014. $65 \mathrm{f}$. Monografia (Licenciatura em artes visuais) - Faculdade Paulista de Artes, São Paulo.

WOOD, Juliette. O livro celta da vida e da morte. São Paulo: Editora Pensamento, 2011. 